\title{
Value of Bone marrow Examination in Pyrexia of unknown origin
}

\author{
Jha $\mathrm{A}^{1}$, Sarda $\mathrm{R}^{2}$ \\ ${ }^{I}$ Department of Pathology, Maharajgunj Medical Campus, Institute of Medicine, Maharajgunj, Kathmandu, Nepal \\ ${ }^{2}$ Department of Pathology, University of Wiskonsin Hospital and Clinics, 600 Highland Ave, Madison, Wisconsin, USA
}

\author{
Keywords: \\ PUO; \\ Bone marrow examination; \\ Hematological \\ malignancy; \\ Infection
}

\begin{abstract}
Background: Pyrexia of unknown origin is a common diagnostic dilemma. Series of diagnostic modalities are required to arrive at diagnosis. Bone marrow examination is one of the common tests implicated in the diagnosis in combination with other diagnostic modalities. Present study has attempted to explore the causes of pyrexia of unknown origin based on bone marrow morphological study.
\end{abstract}

Materials and Methods: In a one year prospective study conducted at Manipal Teaching Hospital, Pokhara, Nepal; bone marrow aspiration and biopsy was performed and evaluated morphologically, in 57 patients fulfilling the criteria of classic pyrexia of unknown origin.

Results: In $42 \%$ cases; specific diagnosis could be made and hematological neoplasm was the most common finding followed by megaloblastic anemia, hypoplastic anemia and one case each of hemophagocytosis, malaria and tuberculosis. Acute leukemia was the most frequently encountered hematological malignancy followed by multiple myeloma, chronic myeloid leukemia, essential thrombocythemia and myelodysplastic syndrome.

Conclusion: Morphological examination of bone marrow has important role in diagnosis of pyrexia of unknown origin. However, yield of diagnosis can be increased if it is combined with other diagnostic modalities including radiological, microbiological and serological tests.

\section{INTRODUCTION}

Pyrexia of Unknown Origin (PUO) means fever that does not resolve spontaneously in the period expected for self-limited infection and the cause of which cannot be ascertained despite considerable diagnostic effort. Reported cases of PUO exceed 200, and fall into diverse sub-specialty categories. There are no algorithms and few

\section{Correspondence:}

Dr Abhimanyu Jha, MD, Associate Professor,

Maharajgunj Medical Campus, Tribhuvan Univeristy, Institute of Medicine,

Maharajgunj, Kathmandu, Nepal.

Email:jhaabhimanyu@yahoo.com clues that reliably suggest or exclude particular diagnoses. ${ }^{1}$ The diagnostic spectrum of PUO is changing over time and PUO remains the diagnostician's challenge. ${ }^{2}$

The response of the bone marrow varies, depending upon infective and noninfective causes. Bone marrow modifications resulting from infection and systemic disease can be studied by analysis of morphology \& etiology, and can impart great influence in the management of patients with fever. In present study an attempt has been made to find out the causes of PUO based on bone marrow morphology. 


\section{MATERIALS AND METHODS}

All the cases of classic PUO of one year duration coming to Manipal Teaching Hospital, Pokhara, fulfilling the criteria of Petersdorf $\mathrm{RG}$ et $\mathrm{al}^{2}$ were included in the study. The criteria of inclusion were: Fever $38.3^{\circ} \mathrm{C}\left(101^{0} \mathrm{~F}\right)$ or higher on multiple days lasting for more than 3 weeks and diagnosis uncertain after appropriate initial investigations of 3 days into hospitalization or 3 outpatient visits. ${ }^{3}$ Pertinent clinical, radiological and laboratory findings were recorded. Both bone marrow aspiration (BMA) and biopsy (BMB) were performed from posterior iliac crest after taking informed consent by standard method under aseptic precautions. For cytological studies trail smear and crush smear were made and biopsy specimen after fixation into $10 \%$ formalin and decalcification processed for histopathological studies.

In each case, for cytological study the bone marrow smears were stained with Leishman stain. Myeloperoxidase and Periodic Acid Schiff (PAS) stain were also used in cases of acute leukemias. In suspected tuberculosis Zeihl-Neelsen (ZN) stain was also performed. It was a cross sectional study, the obtained data were collated and results were tabulated. The data were analyzed by measures of central tendency.

\section{RESULTS}

Bone marrow examinations of 74 patients with fever were performed, however; only 57 cases fulfilled the criteria of inclusion. Thirty cases were males and 27 were females with a male to female ratio of 1.22:1. Age distribution is shown in table 1 . Median age was 30 years. Six cases were children $(<15$ years) and 10 cases were seen in elderly $(>65$ years). Duration of fever was 21 to 365 days with most common being 21 to 30 days. Results of the morphological diagnosis of PUO in 57 patients are shown in table 2.

In one case $\mathrm{BMB}$ showed epithelioid granuloma but Z-N stain for acid fast bacilli (AFB) was negative, however, liver biopsy in the same patient showed caseating granuloma with positive AFB, favoring the diagnosis of tuberculosis. In one case BMA smear showed gametocytes of Plasmodium falciparum. Hematological malignancies were seen in 11 cases (Table 3 ).

In 49 cases bone marrow aspiration and biopsy diagnosis was same. However, in cases of tuberculosis and malaria the findings were inconsistent. Granuloma was seen in the $\mathrm{BMB}$ and malaria parasite was seen in BMA. In the former BMA showed reactive myeloid hyperplasia and in the latter $\mathrm{BMB}$ revealed erythroid hyperplasia. In six cases BMB was not available for correlation.

\section{DISCUSSION}

Currently there are various definitions of PUO depending on clinical setting such as classical, nosocomial, neutropenic and PUO in HIV patients. ${ }^{4}$ However, definition given by Petersdorf is widely used. In present study the definition of classical PUO was used for case selection. ${ }^{3}$ Diagnosis of PUO requires multidisciplinary approach and battery of tests are required. Although in present study an attempt has been made to diagnose the causes of PUO based on bone marrow morphology alone.

Specific cause of PUO could be ascertained in $24(42 \%)$ cases based on BM morphology. In descending order of frequency, they include hematological neoplasm, megaloblastic anemia, hypoplastic anemia, malaria, tuberculosis and hemophagocytosis. In most of the studies infection constituted the commonest cause of PUO followed by neoplasm, and collagen vascular disease unlike this study. ${ }^{1,3,5}$ However present study was based only on bone marrow morphology unlike other studies. In prospective multicentric study conducted by Elisabeth et al and Netherlands's FUO study group in 167 patients, showed infection as a leading cause (26\%) followed by neoplasm and non-infectious inflammatory disease (13\% \& $24 \%$ respectively). Miscellaneous cause accounted 5\% and 30\% of cases were undiagnosed despite every effort. ${ }^{6}$

About $30 \%$ of patients with malignancy develop fever at some point during the course of their disease. There are varieties of proposed causes of fever in malignancy such as tumor mass, infection, drugs, and autoimmune diseases. Tumor necrosis

Table 1: Age distribution of patients with PUO

\begin{tabular}{ccc}
\hline Age group (years) & No. of cases & \% \\
\hline $1-14$ & 6 & 10.5 \\
$14-44$ & 32 & 56 \\
$45-64$ & 9 & 16 \\
$>65$ & 10 & 17.5 \\
\hline Total & 57 & 100 \\
\hline
\end{tabular}

Table 2: Morphological changes in bone marrow

\begin{tabular}{clcc}
\hline S.N. & \multicolumn{1}{c}{ Diagnosis } & $\begin{array}{c}\text { No. of } \\
\text { Cases }\end{array}$ & \% \\
\hline 1 & Neoplastic & 11 & 19.25 \\
2 & Eosinophilia & 1 & 1.75 \\
3 & Erythroid hyperplasia (EH) & 4 & 7.01 \\
4 & $\begin{array}{l}\text { EH with Megaloblastic } \\
\text { changes }\end{array}$ & 7 & 12.3 \\
\hline 5 & Falciparum malaria & 1 & 1.75 \\
6 & Hemophagocytosis & 1 & 1.75 \\
7 & Hypoplastic marrow & 3 & 5.26 \\
8 & Reactive myeloid hyperplasia & 25 & 44 \\
9. & Within normal limit & 3 & 5.26 \\
10 & Tuberculosis & 1 & 1.75 \\
\hline & Total & 57 & 100 \\
\hline
\end{tabular}




\begin{tabular}{llcc}
\multicolumn{3}{l}{ Table 3: Distribution of malignancies } \\
\hline S.N. & \multicolumn{1}{c}{ Diagnosis } & $\begin{array}{c}\text { No. of } \\
\text { cases }\end{array}$ & $\%$ \\
\hline 1 & Acute myeloid leukemia (AML) & 6 & 54.54 \\
\hline 2 & Chronic myeloid leukemia (CML) & 1 & 9.09 \\
\hline 3 & Essential thrombocythemia (ET) & 1 & 9.09 \\
\hline 4 & Multiple myeloma (MM) & 2 & 18.18 \\
\hline 5. & $\begin{array}{l}\text { MDS, Refractory anemia with ring } \\
\text { sideroblast (RAR) }\end{array}$ & 1 & 9.09 \\
\hline & Total & 11 & 100 \\
\hline
\end{tabular}

Table 4: Comparison of infection and neoplasm as cause of PUO in 4 studies

\begin{tabular}{lcc}
\hline \multicolumn{1}{c}{ Studies } & $\begin{array}{c}\text { Infection, No. } \\
\mathbf{( \% )}\end{array}$ & $\begin{array}{c}\text { Neoplasm, } \\
\text { No. (\%) }\end{array}$ \\
\hline Petersdorf RG et al $^{2}$ & $36(36)$ & $19(19)$ \\
\hline Knockaert DC et al $^{8}$ & $4(8.8)$ & $2(4.4)$ \\
\hline Haq SA et $\mathrm{al}^{9}$ & $134(63.21)$ & $27(12.74)$ \\
\hline Present study & $2(18.18)$ & $11(19.25)$ \\
\hline
\end{tabular}

is one of the possible causes of fever in malignancy. ${ }^{7}$ In this study $19.25 \%(n=11)$ showed hematological malignancies in their bone marrow. Most common neoplasm was AML, 6 cases $(54.54 \%)$. Multiple myeloma accounted in 2 cases (18.18\%), CML, MDS and Essential thrombocythemia constituted 1 cases each (each 9.09\%) as shown in table 3 . Distribution of neoplasms in various series is shown in table 4. ${ }^{1,6,8,9}$ In present study no solid tumors or metastatic tumors were detected in bone marrow examination. This could be due to widespread use of USG and CT scan for the early diagnosis of solid tumors. In Haq SA et al series leukemia constituted the commonest malignancy causing PUO. ${ }^{9}$ In a prospective multicentric study in 167 patients with PUO by De Kleijn et al and colleague, neoplasm constituted $12.6 \%$ of total cases. Hematological malignancies were $66.66 \%$ of total neoplastic cases. Hodgkin disease was the commonest neoplasm (35.7\%). Acute leukemia accounted only one case (7.14\%). ${ }^{6}$ In the study of Knokaert et al and colleagues, $7 \%$ cases $(n=199)$ were malignancy as a cause of PUO. Hematological malignancy constituted 6 cases (3\%) and solid tumors constituted 8 cases (4\%). Among the hematological malignancies AML was the commonest, 3 cases $(50 \%)$. Multiple myeloma constituted 1 case $(16.66 \%)$ and Hodgkin disease 2 cases (33.33\%). ${ }^{10}$

In present study, 7 cases (12.3\%) in their bone marrow showed erythroid hyperplasia with megaloblastic changes. Erythroid hyperplasia alone was seen in 4 cases (7.01\%). Megaloblastic anemia as the cause of PUO is usually not mentioned in current texts. In the era before vitamin B12 treatment, fever was recorded in upto $79 \%$ of patients with pernicious anemia11 and in Davidson's series it occurred in $22 \%$ of patients. ${ }^{12}$ Davidson related the degree and frequency of fever to the severity of anemia. According to
McKee LC et al. fever in megaloblastic anemia is due to increased activity of megaloblastic marrow, and fever was present in about $40 \%$ of patients. ${ }^{13}$ Although the mechanism of fever in this condition is unknown its occurrence is not rare. ${ }^{14}$ Erythroid hyperplasia, megaloblastic changes and Coomb's test positive hemolytic anemia are also seen in CVD as described by Rosenthal NS et al. ${ }^{15}$ In his series $50 \%$ marrow specimen showed megaloblastic maturation $(\mathrm{n}=32)$. In present study one case showing megaloblastic changes in bone marrow was ANA positive. Two cases in present study showed positive direct Coomb's test. One of them had megaloblastic marrow and other had only erythroid hyperplasia.

In present study 3 patients (5.26\%) showed hypoplastic marrow. Varieties of drugs, chemicals, toxins, infection, radiation or immune disorders are involved in etiology of hypoplastic marrow. Bone marrow examination alone is not sufficient to point out the cause of hypoplastic marrow. In patients with hypoplastic marrow, bacterial and fungal infections are common secondary to neutropenia.

Hemophagocytosis was seen in one case (1.75\%) in present study. Viruses such as Herpes virus, Parvovirus-B19, CMV, EBV, and HIV are most commonly associated with hemophagocytosis. Although bacteria such as Salmonella, E.coli, Brucella, Legionella, and parasites such as Toxoplasma, Leishmania, and Malaria are also responsible for hemophagocytosis. ${ }^{16-19}$ Yves A et al reported 11 cases of NHL presenting with hemophagocytosis in the bone marrow. ${ }^{20}$ Familial hemophagocytic lymphohistiocytosis develop early in life; about $70 \%$ present at less than 1 year of age. ${ }^{21}$ No specific cause of hemophagocytosis was identified in this study.

In present study only two cases of established infections detected. One case (1.75\%) had epithelioid granuloma in the bone marrow with negative AFB. In a study done by Farhi DC et al in immunocompromised patients, 14 of 27 bone marrow biopsy showed granuloma but only one of them was positive for AFB. ${ }^{22}$ In a clinicopathologic analysis of 58 cases, by Bodem CR et al, 4 cases had tuberculosis with granuloma in the bone marrow, but only 2 of 4 cases showed AFB. ${ }^{23}$ In a study done by Volk EE et al, $15 \%$ of patients had granuloma in the bone marrow but none of them showed organism by special stain. ${ }^{24}$ So, it is not uncommon to find that organisms are absent by special stains despite presence of granuloma. Bone marrow granulomas occur as a non-specific response to a persistent antigenic stimulation and have been identified in a wide range of illness. No morphologic features were apparent that clearly distinguished one cause of granuloma from other in Bodem CR et al series. ${ }^{23}$ The best possible evidence to establish the etiology of marrow granuloma would require that a second biopsy, performed after specific therapy or following removal of etiologic factor demonstrate disappearance of granuloma. ${ }^{23} \mathrm{~A}$ repeat biopsy is, however, 
subject to the limitations of sampling error inherent in the biopsy procedure. Bone marrow morphology in patients with tuberculosis showed reactive myeloid hyperplasia in the study of Singh KJ et al. which supports the findings of present study. ${ }^{25}$

Mirdha BR et al identified malaria in the bone marrow of 8 of 120 cases with PUO. Five cases were Plasmodium vivax and 3 cases were Plasmodium falciparum. ${ }^{26}$ In present study only one case was diagnosed to have malaria in the bone marrow and it was Plasmodium falciparum. The commonly used laboratory method for diagnosis of malaria in this part of world is microscopic examination of Romanowsky's stained thin and thick peripheral blood film. However, its sensitivity is directly proportional to the microscopic skill, screening time and staining. However diagnostic bone marrow examination is often performed when a patient with suspected infection has persistent fever. Malaria surveys based on microscopic examination of the blood film do not always detect chronic, low-grade infection due to either scanty parasitemia or the patient's immunity. The free malarial parasite phagocytosed plasmodia, free hemozoin pigments, and pigmented leukocytes are commonly seen in bone marrow aspirates as compared to blood film. It is understood that till date complete consensus on routine diagnostic use of bone marrow for the diagnosis of malaria have not been achieved due to its inherent limitations. But, bone marrow examination still has a valuable place in the investigation of patients with suspected malaria. ${ }^{26}$

Reactive myeloid hyperplasia constituted 25 cases (44\%). This condition is non-specific morphological change of bone marrow in response to various inflammatory and infective conditions. No specific etiological agents were identified. Bone marrow responds to inflammation by accelerated release of cells from post mitotic reserve pool caused by IL-1 \& TNF and associated with an increase in numbers of more immature granulocytes. Severe bacterial infections lead to granulocytic hyperplasia with or without maturing cells. Toxic granules may be evident in the cytoplasm of the granulocytes. Erythropoiesis may be depressed with reduced sideroblastic granulation in erythroblasts. Megakaryocytes are increased with bare megakaryocytes. Macrophages are increased and may be associated with hemophagocytosis. ${ }^{27}$ Bone marrow culture in association with bone marrow morphology would be more useful in suspected infectious etiology. ${ }^{28}$

Rosenthal NS et al reported granulocytic hyperplasia as one of the features of CVD. ${ }^{15}$ One of the case of reactive myeloid hyperplasia in present study had positive ANA. Wain J et al reported myeloid hyperplasia in cases of enteric fever. ${ }^{29}$

Eosinophilia of bone marrow was seen in one of the case $(1.75 \%)$ in present study. Peripheral blood did not show any eosinophilia. Bone marrow aspirate and biopsy showed increased eosinophils with normal morphology. The reason behind absent peripheral blood eosinophilia could be due to lag between induction of eosinophil development and emigration from marrow resulting in delayed blood eosinophilia. Various helminthic infections, allergic disorders, endocrine disorders, drugs, CVD, and neoplastic disorders are associated with eosinophilia. However, in present study no specific cause was found. ${ }^{30}$

\section{CONCLUSION}

Bone marrow examination is an integral part of investigation of PUO, however, morphological finding alone would not be sufficient, rather a supplementation of bone marrow culture would be more contributory. In present study morphological examination alone contributed to diagnosis of $42 \%$ of cases of PUO with hematolgogical malignancy being the most common cause. Megaloblastic anemia, hypoplastic anemia, malaria, tuberculosis and hemophagocytosis were some of the entities which could be diagnosed morphologically.

\section{REFERENCES}

1. Arnow PM, Flaherty JP. Fever of Unknown Origin. The Lancet 1997;350:575-80.

2. Petersdorf RG. Fever of Unknown Origin, An old friend revisited. Arch Intern Med 1992;152:21-2.

3. Root RK, Petersdorf RG. Fever of Unknown Origin. In: Root RK, Waldvogel F, Corey L, Stamm WE (eds). Clinical Infectious Diseases. A Practical approach. Oxford Medical Publications: New York;1999.pp459-69.

4. Jha A, Adhikari RC, Sarda R. Bone marrow Evaluation in Patients with Fever of Unknown Origin. Journal of Pathology of Nepal 2012;2:231-40.

5. McCarthy PL. Fever. Pediatrics 1999;11:49-55

6. De Kleijn EMHA, Vandenbroucke JP, van Der Meer JWM, and the Netherlands FUO Study group. Fever of Unknown Origin (FUO)-I. A prospective multicenter study of 167 patients with FUO, using fixed epidemiologic entry criteria. Medicine 1997;76:392-400.

7. John WJ, Foon KA, Patchell RA. Paraneoplastic Syndrome. In: Devita Vincent T, Hellman Samuel, Rosenberg SA. Cancer, principles and practice of oncology. Eds5. Lippincott-Raven: Philadelphia;1997.2148pp.

8. Knockaert DC, Vanneste LJ, Bobbaers HJ. Recurrent or Episodic Fever of Unknown origin. Review of 45 cases and Survey of the Literature. Medicine 1993;72:184-96.

9. Haq SA, Alam MN, Hossain SM et al. A study of prolonged pyrexia in Dhaka. Bangladesh Med. Res. Counc. Bull.1996;22:33-42.

10. Knockaert DC, Vanneste LJ, Vanneste SB, Bobbaers HJ. Fever of Unknown Origin in the 1980s: An update of the Diagnostic Spectrum. Arch Intern Med 1992;152:51-5.

11. Cabot RC Cabot RC. Pernicious anemia. In: Osler W, McCrae T (eds). A System of Medicine, Vol. 4. Frowde: London; 1908.612pp

12. Davidson S. Clinical picture of pernicious anaemia prior to the introduction of liver therapy in 1926 and Edinburg subsequent to 1944. Br Med J 1957;1:141-3.

13. Mckee LC. Fever in megaloblastic anemia. South Med J 1979;72:1423-4.

14. Meir M, Shlomi M, Evgnia R, Zvi F. A man with prosthetic valve, anaemia, fever, and splenomegaly. Lancet 1996;348:1216. 
15. Rosenthal NS, Farhi DC. Bone marrow findings in connective tissue diseases. Am. J Clin Pathol 1989;92:650-4.

16. Diebold J, Molina T, Camilleri-Broet S, Tourneau A le, Audouin J. Bone marrow manifestations of infections and systemic diseases observed in bone marrow trephine biopsy. Histopathology 2000;37:199-211.

17. Shirono K, Tsuda H. Parvovirus B19-associated hemophagocytic syndrome in healthy adults. British J. Haematol 1995;89:923-6.

18. McKenna RW, Risdall RJ, Brunning RD. Virus associated hemophagocytic syndrome. Hum Pathol 1981;12:395-9.

19. Janka G, Imashuku S, Elinder G, Schneider M, Henter JI. Infectionand Malignancy-Associated Hemophagocytic Syndromes. Hematology Oncology Clinics of North America 1998;12:435-44.

20. Allory $\mathrm{Y}$, Challine D, Haioun $\mathrm{C}$ et al. Bone marrow involvement in Lymphomas with Hemophagocytic Syndrome at Presentation. A clinicopathologic Study of 11 patients in a Western Institution. Am J Clin Pathol 2001;25:865-74.

21. Henter JI, Arico M, Elinder G, Imashuku S, Janka G. Familial hemophagocytic lymphohistiocytosis. Primary hemophagocytic lymphohistiocytosis. Hematology/ Oncology Clinics of North America 1998;12:417-33.

22. Farhi DC, Mason UG, Horsburg CR. The Bone marrow in Disseminated Mycobacterium avium-intracellulare Infection. Am J Clin Pathol 1985;83:463-8.
23. Bodem CR, Hamory BH, Taylor HM, Kleopfer L. Granulomatous bone marrow disease. A review of the literature and clinicopathologic analysis of 58 cases. Medicine1983;62:373-83.

24. Volk EE, Miller ML, Kirkley BA, Washington JA. The diagnostic usefulness of bone marrow cultures in patients with Fever of Unknown Origin. Am J clin Pathol 1998;110:150-3.

25. Singh KJ, Ahluwalia G, Sharma SK, Saxena R, Chaudhary VP, Anant M. Significance of Hematological Manifestations in patients with tuberculosis. J Assoc Physicians India 2001;49:788-94.

26. Mirdha BR, Smantray JC, Mishra B, Xess I. Bone marrow Examination for Identifying Malaria in Fever of Unknown Origin. J Assoc Physicians India 1999;47:177-9.

27. Bain BJ, Clark DM, Lampert IA. Bone Marrow Pathology: Infection and Reactive Changes. 2nd ed. Blackwell Science:Oxford;1996. pp51-87.

28. Jha A, Sarda R, Gupta A, Talwar OP. Bone marrow culture Vs Blood Culture in FUO. J Nepal Med Assoc 2009;48:135-8.

29. Wain J, Bay PVB, Vinh H et al. Quantitation of bacteria in bone marrow from patients with typhoid fever: Relationship between counts and clinical features. J Clin. Microbiol 2001;39:1571-6.

30. Ryan DH, Cohen HJ. Bone Marrow Aspiration and Morphology. In: Hoffman Ronald, Benz Edward J, Shattil Sanford J, et al. Hematology. Basic Principles and Practice. 3rd ed. Churchill Livingstone: Philadelphia;2000.pp2460-8. 